\title{
Task and Vehicle Dynamics Based Assessment of Motion Cueing Requirements
}

\author{
William W. Chung \\ Science Applications International Corporation, Hampton, VA 23666 \\ Judith Bürki-Cohen ${ }^{\dagger}$ \\ USDOT/Volpe National Transportation Systems Center, Cambridge, MA 02142 \\ and \\ Tiauw H. Go ${ }^{\ddagger}$ \\ Massachusetts Institute of Technology, Cambridge, MA 02139
}

One significant difference between real and simulated flight on the ground are the stimuli or cues provided to the pilot. Due to physical and/or cost constraints, it is nearly impossible to match all the cues experienced in the air in ground-based simulators. Motion cues, in particular, are severely affected by the limits imposed on the ground, such as the extent of travel and the dynamics bandwidth. Researchers have been struggling for decades to develop a better understanding on how pilots' behavior and performance in the simulator are affected by these limitations, and to determine the motion-cueing requirements appropriate to the purposes of the simulation. It has been demonstrated that motion cues can affect pilot-vehicle performance and pilot behavior in ground-based simulators. However, whether motion cues affect behavior and performance appears to be a function of pilot task, vehicle dynamics, and cueing quality (of motion and other cues). The experimental design also greatly affects the validity (whether the data answer the research question) and reliability (whether the results can be replicated) of a study. This paper is developing a systematic approach to re-examine past studies in an effort to develop a comprehensive understanding of the effects of motion in ground-based flight simulators.

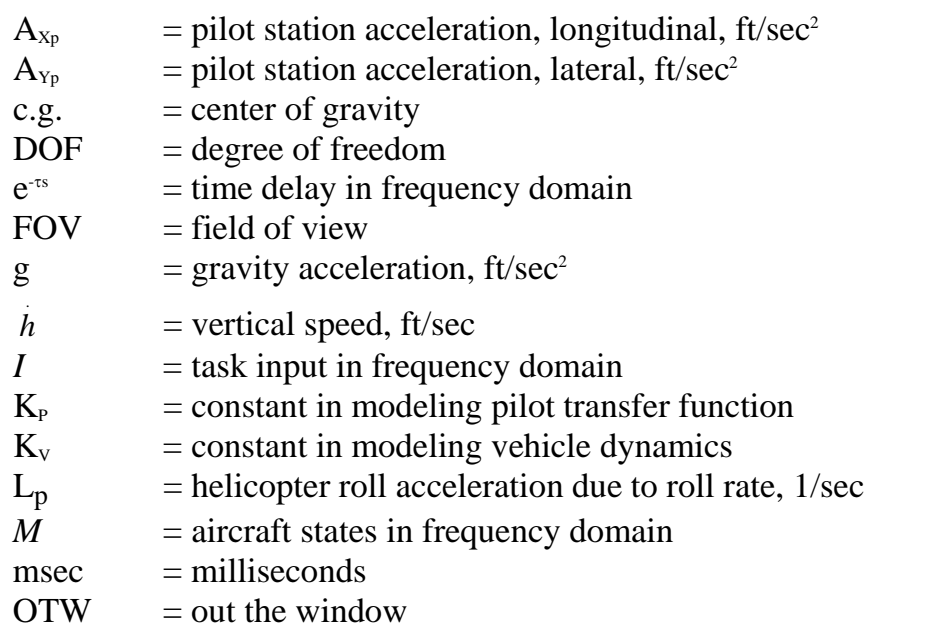

\footnotetext{
*Aerospace Engineer. Spatial Technologies \& Concept Division, 130 Research Drive. Senior Member AIAA.

${ }^{\dagger}$ Engineering Psychologist, Operator Performance and Safety Analysis Division, DTS-79, 55 Broadway. Member AIAA.

${ }^{\ddagger}$ Aerospace Research Engineer, Center for Transportation and Logistics, 37-219, 77 Massachusetts Avenue. Member AIAA.
} 


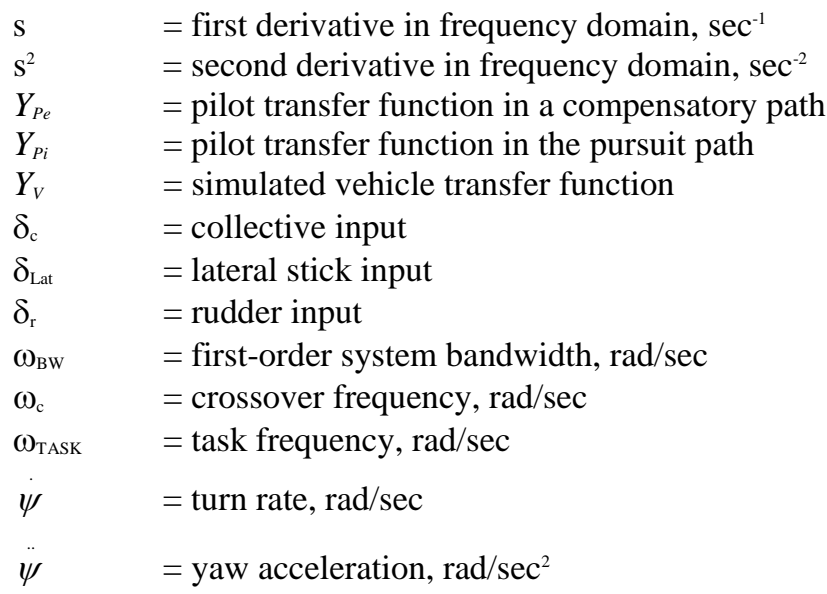

\section{Introduction}

It is well known that human pilots will quite successfully adapt their behavior to many different control situations, and in the process optimize the pilot-vehicle performance for the task. ${ }^{1}$ Due to the artifact of groundbased flight simulations, e.g., visual transport delay, scene content, and specific force cues, the exact flying experience in a real cockpit may not be fully reproduced in ground-based flight simulators. Pilots are expected to change their control strategy and behavior depending on perceived simulation cues under a given task. How pilots adapt to simulation cues, and what the requirements are for different types of simulation cues to fulfill different missions, has been the focus of many studies. This is particularly true for motion cues. Due to the travel limits imposed by the motion platform, all ground-based simulators are restricted to issuing attenuated motion commands. These commands use frequency-dependent motion-drive algorithms, ${ }^{2,3}$ which depend on both the dynamics of the task to be flown and the dynamics of the simulated airplane. The motion cueing characteristics need to be carefully considered when designing and analyzing the results of an experiment. ${ }^{1}$

A systematic approach is warranted to analyze and reach practical conclusions from the vast body of literature available on motion cueing in ground-based flight simulators. Without identifying all key factors that directly influence pilots' control behavior in ground-based flight simulations and considering them in the context of the entire controlled system, conclusions drawn from individual experiments may only reveal local effects due to specific simulation cueing elements. This will limit the lessons that can be learned from these studies.

When considering an experiment, it is also very important to examine whether the design is valid and reliable. The term "validity" relates to whether the experiment does indeed answer the question posed by the experimenter, or whether the results are an artifact of a design flaw. "Reliability" refers to the ability to replicate an experiment and produce the same results, which would show that the results are due to the intended independent variables chosen by the experimenters instead of some accidentally introduced variability.

Based on the above factors, this paper proposes an approach to review past studies related to motion cueing. The paper summarizes the initial steps of the approach, demonstrates their application to a few selected studies, and makes recommendations for future elaboration of the approach. Note that pilots respond to a combination of simulation cues presented to them during simulated flight. Although the focus of this paper is simulator motion, future expansions of the approach described in this paper will also consider the fidelity of cues such as those provided, e.g., by the control-force and sound systems.

\section{Task and Vehicle Dynamics}

Using a closed-loop control system analogy, $\mathrm{McRuer}^{4}$ classifies tasks into three types, i.e., compensatory, pursuit, and precognitive, as shown in Fig. 1. In a compensatory task, the pilot reacts to system-output errors, exercising closed-loop feedback control of the airplane. In a pursuit task, in addition to responding to taskperformance error, the pilot also uses the information on the state of the system when applying control inputs, e.g., the state of the lead aircraft to be followed in a formation flight. Most of the tasks performed in ground-based simulators are pursuit tasks. In pursuit tasks, using information from the out-the-window (OTW) visual scene or displays, pilots combine two control approaches, namely, open-loop feed-forward control using target-state information to generate lead, and closed-loop compensatory control using error information to correct tracking errors. A third type of task, described as precognitive, emerges when pilots are so familiar with the vehicle 
characteristics that they can choose from a set of previously learned responses, performing the task in an open-loop programmed-control-like fashion.

From Fig. 1, transfer functions between airplane states, $\mathrm{m}$, and task, i, and between airplane states and error, e, can be written as shown in Eqs. (1) and (2). In these equations, if the pursuit path is dominant and pilots can achieve an openloop response of $\mathrm{Y}_{\mathrm{Pi}} \mathrm{Y}_{\mathrm{V}}=1$, then $|\mathrm{M}| /|\mathrm{I}| \rightarrow 1$, and $|\mathrm{E} / / \mathrm{I}| \rightarrow 0 .{ }^{1}$ Estimated pilot transfer functions according to this approach are summarized in Table 1.

$$
\begin{aligned}
\frac{M}{I} & =\frac{Y_{V}\left(Y_{P i}+Y_{P e}\right)}{1+Y_{V} Y_{P e}} \\
\frac{E}{I} & =\frac{1-Y_{V} Y_{P i}}{1+Y_{V} Y_{P e}}
\end{aligned}
$$

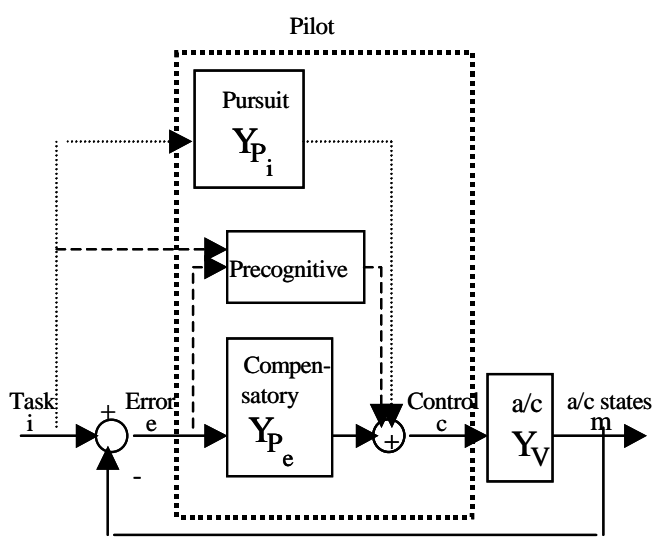

Figure 1. Closed-loop representation of pilotvehicle relationship according to type of task.

Table 1. Estimated primary functions of pilots in a pursuit task

\begin{tabular}{|l|l|l|}
\hline Vehicle Transfer Function, $\mathbf{Y}_{\mathrm{V}}$ & $\begin{array}{l}\text { Pilot Transfer Function, } \\
\mathbf{Y}_{\mathbf{P e}}\end{array}$ & Pilot's Primary Function \\
\hline Constant: $\mathrm{K}_{\mathrm{V}}$ & $1 / \mathrm{K}_{\mathrm{V}}$ & Gain \\
\hline Rate system: $\mathrm{K}_{\mathrm{V}} / \mathrm{s}$ & $\mathrm{s} / \mathrm{K}_{\mathrm{V}}$ & Rate \\
\hline $\begin{array}{l}\text { Rate system with a time constant, } 1 / \mathrm{a}: \\
\mathrm{K}_{\mathrm{V}} / \mathrm{s}(\mathrm{s}+\mathrm{a})\end{array}$ & $\mathrm{s}(\mathrm{s}+\mathrm{a}) / \mathrm{K}_{\mathrm{V}}$ & $\begin{array}{l}\text { Rate plus a lead } \\
\text { Rate plus a gain, low frequency }\left(\omega_{\text {Task }}<<\mathrm{a}\right) \\
\text { Acceleration, high frequency }\left(\omega_{\text {Task }}>>\mathrm{a}\right)\end{array}$ \\
\hline Acceleration system: $\mathrm{K}_{\mathrm{V}} / \mathrm{s}^{2}$ & $\mathrm{~s}^{2} / \mathrm{K}_{\mathrm{V}}$ & Acceleration \\
\hline
\end{tabular}

If, however, it is assumed that the compensatory path is dominant in pilots' control strategy, i.e., $\mathrm{Y}_{\mathrm{Pi}}=0$, the closed-loop system is simplified to a single loop as shown in Fig. 2. McRuer and Krendel ${ }^{1}$ modeled the dynamics of a pilot-vehicle feedback control system by quantitatively describing pilot behavior for this type of task. From experimental data they distilled the pilot-vehicle crossover model as shown in Eq. (3), which indicates that pilots adapt their control strategy so as to preserve such open-loop pilot-vehicle characteristics. This pilot-vehicle openloop relationship has been demonstrated in both fixedbase and motion-base flight simulators. ${ }^{5}$

$$
Y_{P e} Y_{V}=\omega_{\mathrm{c}} \mathrm{e}^{-\tau \mathrm{s}} / \mathrm{s}
$$

The approximate pilot transfer functions derived for the control-system set investigated according to this crossover model are shown in Table 2. The table shows how pilots adapt their control behavior or primary function relative to the vehicle dynamics.

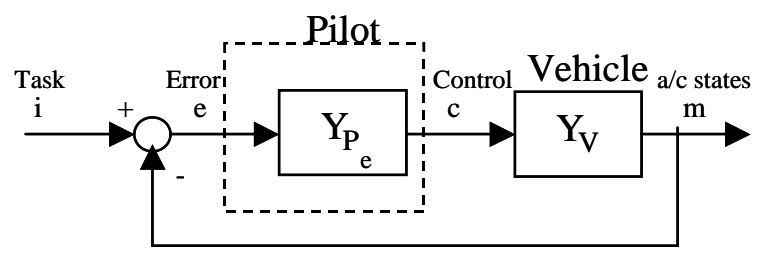

Figure 2. Closed-loop representation of pilot-vehicle relationship in a compensatory task.

Table 2. Estimated primary functions of pilots in a compensatory task according to the crossover model

\begin{tabular}{|l|l|l|}
\hline Vehicle Transfer Function, $\mathbf{Y}_{\mathrm{V}}$ & $\begin{array}{l}\text { Pilot Transfer Function, } \\
\mathbf{Y}_{\mathbf{P e}}\end{array}$ & Pilot's Primary Function \\
\hline Constant: $\mathrm{K}_{\mathrm{V}}$ & $\mathrm{K}_{\mathrm{P}} \mathrm{e}^{-\tau \mathrm{s}} / \mathrm{s}$ & Integrator \\
\hline Rate system: $\mathrm{K}_{\mathrm{V}} / \mathrm{s}$ & $\mathrm{K}_{\mathrm{P}} \mathrm{e}^{-\tau \mathrm{s}}$ & Gain \\
\hline $\begin{array}{l}\text { Rate system with a time constant, } \\
1 / \mathrm{a}: \mathrm{K}_{\mathrm{V}} / \mathrm{s}(\mathrm{s}+\mathrm{a})\end{array}$ & $\mathrm{K}_{\mathrm{P}}(\mathrm{s}+\mathrm{a}) \mathrm{e}^{-\tau \mathrm{s}}$ & $\begin{array}{l}\text { Lead } \\
\text { Gain, low frequency }\left(\omega_{\text {Task }}<<\mathrm{a}\right) \\
\text { Rate, high frequency }\left(\omega_{\text {Task }}>>\mathrm{a}\right)\end{array}$ \\
\hline Acceleration system: $\mathrm{K}_{\mathrm{V}} / \mathrm{s}^{2}$ & & Angular rate or translational velocity \\
\hline
\end{tabular}




\section{Visual Cues}

In ground-based flight simulators, pilots use the aircraft-state and performance-error information acquired from simulation cues, i.e., visual, motion, inceptor cues, and/or aural cues, to generate appropriate control commands to the simulated aircraft. Among them, pilots rely most heavily on visual cues. They provide pilots with spatial orientation and position relative to the tasks. Visual cueing delay due to image generation and transport delay, which used to reduce cue effectiveness, has been improved to an acceptable level. Another technical advance is the availability of wide field-of-view (FOV) display systems that provide peripheral vision. Peripheral vision has been shown to play an important role in the emergence of vection, or the illusion of motion. ${ }^{6}$

\section{Motion Drive Algorithms and Platform Dynamics}

There are three major components in motion drive algorithms. They are high-pass washout filter, tilt compensation, and coordinated crossover logic due to angular motion. ${ }^{3}$ All three components are frequency dependent, and their cueing effects are dependent on the simulated-airplane dynamics and the flying tasks. Highpass washout filters provide good motion phase responses at high frequency. However, for frequencies below the washout-filter frequency, a frequency-dependent phase lead relative to the visual cues is inevitable. Tilt provides a tradeoff for simulating low frequency translational motion cues, which typically demand large travel. Low frequency sway and surge cues are produced by tilting the cockpit and using the gravity to produce the desired specific force. By doing so, simulator travel demand is preserved, but has to be constrained by tilt rate and phase delay stemming from the use of a first-order low-pass filter. Coordinated translational motion to minimize unintended gravity force due to angular motion has been found to improve the motion fidelity in rotorcraft flight simulations. ${ }^{7,8}$ Because low-frequency angular motion has already been attenuated by the application of high-pass filtering, tasks within a frequency range above the tilting frequency are subject to cross feed.

\section{Experimental Validity and Reliability}

In addition to the task and simulator characteristics, the outcome of an experiment is also affected by the experiment design. An experiment is considered "valid" if the design does indeed answer the question it is supposed to answer. For example, data from questionnaires that pilots completed after flying a simulator will not reveal the effect of simulator characteristics on pilot-vehicle behavior and task performance, but only on pilots' conscious perceptions. In fact, if pilots knew which simulator characteristics were manipulated as part of the experiment, their answers may reflect preconceived opinions rather than their actual perceptions during the experiment. Even pilotvehicle performance data collected from the simulator may be misleading if pilots were able to stabilize vehicle performance by adopting a different strategy to compensate for cue deficiencies, e.g. To fully understand the effect of the characteristics compared, it is important to look at pilots' control inputs as well. Finally, for a valid answer to the question of whether a particular simulator characteristic affects the training of pilots to fly the real airplane, it is important to look at how the simulator characteristics affect transfer of training to the airplane rather than just the performance/behavior in the simulator. Vice versa, when the simulator configuration is examined as a tool for pilot proficiency checks, then transfer from the airplane to the simulator needs to be tested. Because measurement of transfer between the simulator and the airplane may not be possible for a variety of reasons, researchers more and more resort to quasi-transfer between the simulator configuration to be tested and a configuration representing a higher degree of fidelity. ${ }^{9,10}$

Reliability refers to the ability of an experiment to be replicated. Reliable data will be obtained in an experiment free of nuisance variables such as drift in simulator performance or measurement-instrument precision and idiosyncratic variability between pilots. The first two can be avoided by careful calibration. Sampling pilots from the same populations may reduce pilot variability (e.g., all captains qualified for the same airplane with a similar background). Counterbalancing across experimental groups may control variability that can not be controlled by the above measures, so that, e.g., the background of the pilots across the different experimental groups averages out. Any residual variability must be washed out by increasing the number of pilots tested. Statistical power analyses will indicate what size of an effect could have been detected given the number of pilots and their idiosyncratic variability. Power analyses are especially important when the experimental results confirm the null hypothesis, i.e., that the experimental manipulation had no effect. Without determining what size of an effect could have been found if there had been one, it is impossible to be sure that no operationally relevant effects have been masked by the variability between pilots. ${ }^{11}$ 


\section{Description of Approach}

Based on understanding the interactions between task and vehicle dynamics and pilot behavior, the effects of visual cues, the fundamental principles of motion-drive algorithms, and the importance of experimental design, the following approach is proposed to review past studies regarding the effect of motion cues.

First, the experimental design is examined to establish the validity and reliability of the results. Then, the nature of the tasks performed by the pilots participating in the investigation is determined. This provides information on the control strategies pilots need to adopt to complete the task, i.e., to achieve an open-loop pilot-vehicle response of $\mathrm{Y}_{\mathrm{Pi}} \mathrm{Y}_{\mathrm{V}}=1$ for pursuit tasks, or of $Y_{P e} Y_{V}=\omega_{\mathrm{c}} \mathrm{e}^{-\tau \mathrm{s}} / \mathrm{s}$ (Eq. (3)) for compensatory tasks. The estimated pilot functions for different vehicle dynamics are listed in Table 1 for pursuit tasks and Table 2 for compensatory tasks. Next, the quality of the simulation cues used in the investigation is considered. For visual cues, transport delay and FOV are two key cueing-quality parameters. Others are display resolution, brightness, and scene content. The quality of the motion cues depends mainly on the dynamics of the motion platform, the type of motion drive algorithms, and the duration of the motion transport delays and motion/visual cue lags.

To determine how the different types of simulator cues affected pilot-vehicle performance and/or behavior in past studies, an attempt is made to categorize the type of cues based on pilots' primary function. A cue that is assumed to directly help pilots conform to the estimated primary pilot function is called a principal cue. For example, if pilot's primary function is a rate system, the principal cue is angular rate or velocity. Supplemental cues are cues pilots may use to derive or supplement the principal cue. Based on their role in supporting the flying task, visual cues and motion cues are categorized according to the estimated pilot functions shown in Table 3 . In the reviews of past investigations, we will first examine the effect of the principal cues, and then the effect of the supplementary cues.

Table 3. Available simulation cues according to pilot primary function in a task

\begin{tabular}{|c|c|c|c|c|}
\cline { 2 - 5 } \multicolumn{1}{c|}{} & \multicolumn{2}{c|}{ Principal Cues } & \multicolumn{2}{c|}{ Supplemental Cues } \\
\hline $\begin{array}{c}\text { Pilot Primary } \\
\text { Function }\end{array}$ & Visual & Motion** & Visual & Motion** $^{* *}$ \\
\hline Gain & Attitude or position & None & $\begin{array}{c}\text { Rate or } \\
\text { velocity }\end{array}$ & $\begin{array}{c}\text { Rate or velocity } \\
\text { Acceleration }\end{array}$ \\
\hline Rate & Rate or velocity & Rate or velocity & Acceleration $*$ & Acceleration \\
\hline Lead & Rate or velocity & Rate or velocity & Acceleration* & Acceleration \\
\hline Acceleration & Acceleration* & Acceleration & None & Rate of change of acceleration \\
\hline
\end{tabular}

* Limited by spatial frequency

** Limited by motion platform characteristics and travels

\section{Review of Past Studies}

\section{A. Review Study \#1: Schroeder's yaw experiment ${ }^{12}$}

\section{Validity and Reliability}

The study provides valid answers to the question of what are the effects of different types and levels of rotational and translational motion on pilot-vehicle performance, pilot workload, and pilots' subjective motion-fidelity and handling-quality perception in a helicopter simulator, by collecting data on each of these dependent variables. The paper does not explicitly state whether precautions were taken to exclude pilot bias. Each pilot served as his or her own control experiencing all simulator motion configurations. This kept the between-group variability low and indeed, a number of significant effects were found performing a 2x2 (translational vs. rotational motion, each present or absent) repeated measures analysis of variance despite the small number of pilots ( 6 for the first and 5 for the second task). No power analyses are presented, so the effect size that could have been found in the cases where none was found remains unknown. The order of presentation of the different configurations, which may affect the results due to pilot adaptation to simulator characteristics in a within-subject experiment, was randomized across pilots to control for adaptation effects. Pilot stimulation by the simulator is carefully described and was presumably stable during the experiment. In general, it is expected that these results are reliable and could be replicated. 


\section{Effect of Motion Cues}

1) Task: A $15^{\circ}$ yaw offset and a $180^{\circ}$ hover turn of a rotorcraft. Both tasks are compensatory since the offset error is clearly presented by OTW visual cues (Fig. 3).

2) Vehicle dynamics: The rotorcraft's yaw response is a first-order rate-command system, as shown in Eq. (4), which means that pilots' yaw command will result in a lagged yaw-rate response. According to Table 2, this is a rate system with a time constant. Therefore, the estimated pilot transfer function is of $\mathrm{K}_{\mathrm{P}}(\mathrm{s}+\mathrm{a}) \mathrm{e}^{-\tau \mathrm{s}}$ type and the primary function of the pilot depends on the task frequency. There is a sway and surge coupling due to yaw acceleration and yaw rate, as given in Eqs. (5) and (6), respectively.

$$
\begin{gathered}
\dot{\psi}=\frac{0.494 \delta_{r}}{s+0.27} \\
A_{Y p}=4.5 \ddot{\psi} \\
A_{X p}=-4.5 \dot{\psi}^{2}
\end{gathered}
$$

3) Visual cues: The experiment had $\pm 40^{\circ}$ FOV with a clearly marked target pole and background to provide heading error, and turn rate information as shown in Fig. 3. Visual cueing had a transport delay of 60 msec.

4) Motion cues: Both full and no motion cues were applied in the yaw and translational degrees of freedom (DOF). Equivalent time delays for each motion DOF due to the motion system were $130 \mathrm{msec}$ for yaw and sway, and 170 msec for surge.

5) Conclusions from the study: The study found full yaw motion cues (no attenuation) did not have an effect to pilot-vehicle performance (except for a marginal improvement in one of many measures). The results show that lateral motion cues significantly reduced yaw overshoot and pedal workload (root mean square pedal rate). Subjective motion fidelity ratings were significantly improved when translational motion cues were presented.

6) Lessons learned: Table 2 shows that the primary function of the pilot depends on the task frequency. The time histories for both tasks indicate that, for heading stabilization, pilots had a pedal-input frequency of around $0.4 \mathrm{~Hz}$ $(2.5 \mathrm{rad} / \mathrm{sec})$ or higher. This is much higher than the first-order yaw-rate system, which has a bandwidth of 0.27 $\mathrm{rad} / \mathrm{sec}$, and makes the vehicle dynamics more of an acceleration system than a rate system with a lag. Therefore, the pilot's primary function would be closer to providing rate than lead. Table 3 indicates that the principal simulation cue for providing rate is turn rate. The OTW scene would provide heading and turn-rate information, which would be useful for pilots to close the outer heading loop with yaw-rate feedback to augment damping. Motion cues from the yaw DOF would also provide the turn-rate information to the pilot. In addition, since pilots were sitting $4.5 \mathrm{ft}$ in front of the rotational center of the simulated rotorcraft, pilots were also subject to lateral acceleration cues. The study results indicate that yaw rate from platform motion did not help to improve pilot-vehicle performance. Instead, when the lateralacceleration motion cues were added, heading

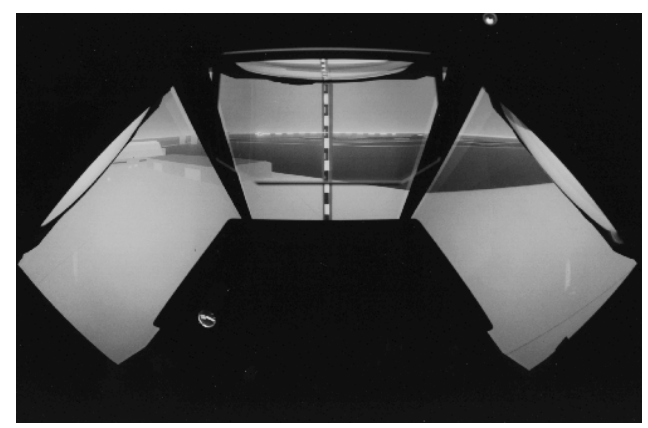

Figure 3. Out-of-window view of an offset heading task from Review Study \#1. stabilization showed an improved damping response. This suggests that lateral-acceleration cues are more useful for the task. In order to achieve the desired damping for heading stabilization, the pilot combines these cues with the turn rate cues from the OTW scene to obtain appropriate yaw-rate feedback.

\section{B. Review Study \#2: Schroeder's vertical experiment ${ }^{12}$}

\section{Validity and Reliability}

The study provides valid data on the effect of varying motion-filter gain and natural frequency on the performance and subjective motion-fidelity perceptions of three experienced pilots flying a helicopter simulation. Each pilot experienced all 10 configurations at least once, in random order to exclude adaptation and learning effects (personal 
communication from author, August 2004). Due to time constraints, only some of the configurations were repeated, which introduced the possibility of experimenter bias. Pilot bias, however, was controlled for by preventing pilots from knowing which configuration they were flying. No statistical or power analyses were performed on the data, so the possibility that some of the results occurred by chance or that the variability within and between pilots has masked some effects cannot be excluded. The author's criterion for accepting a result as reliable was congruence between objective and subjective data.

\section{Effect of Motion Cues}

1) Task: A $10 \mathrm{ft}$ bob-up maneuver of a rotorcraft followed by stabilization in front of a hover target. The task started out as a precognitive task, followed by a compensatory stabilization.

2) Vehicle dynamics: The vertical dynamics off the rotorcraft is a first-order rate command system (Eq. (7)). Therefore, from Table 2, the pilot transfer function for the compensatory part of task is of $\mathrm{K}_{\mathrm{P}}(\mathrm{s}+\mathrm{a}) \mathrm{e}^{-\tau s}$ type.

$$
\dot{h}=\frac{9 \delta_{c}}{s+0.3}
$$

3) Visual cues: The cockpit FOV in the elevation was $10^{\circ}$ up and $15^{\circ}$ down, as shown in Fig. 4. A chin window at the lower right extended the vertical FOV to $-48^{\circ}$. At the initial hover position, the hover target, which was $10 \mathrm{ft}$ above, was in sight. The OTW view contained a hover target for the stabilization task with limited background scene content. The visual cueing transport delay was 60 msec.

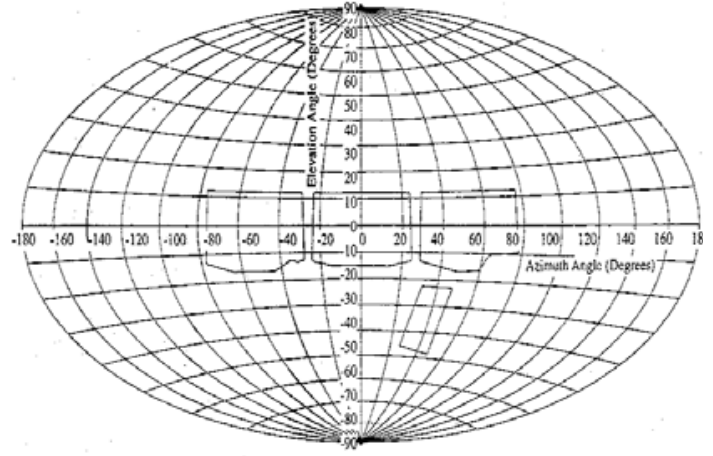

Figure 4. Field-of-view for the vertical bob-up task

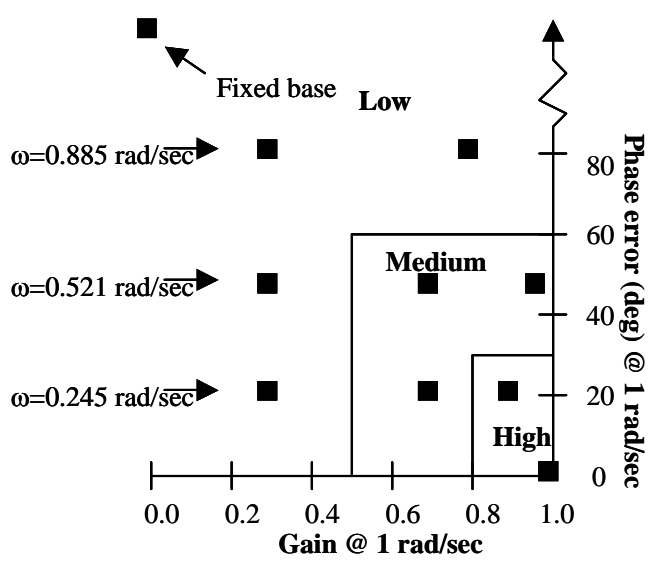

Figure 5. Vertical motion cueing fidelity investigated in Review Study \#2.

4) Motion cues: The vertical motion-cueing fidelity investigated ranged from full-motion to no-motion with different levels of motion attenuation (Fig. 5). ${ }^{12}$ This was achieved by varying the motion command gains and washout filter frequencies. The vertical motion equivalent time delay was $140 \mathrm{msec}$.

5) Conclusions from the study: First, the study found that vertical motion cues appeared to affect pilot-vehicle performance. Second, the study indicates that whether this effect results in improvement or deterioration of pilot performance and behavior is a function of the fidelity or quality of the motion cues.

6) Lessons learned: Table 2 indicates that pilots' primary function depends on the task frequency. The collective time history of the altitude stabilization part of the task after the capture of the desired hover-position showed significant frequency content up to $0.4 \mathrm{~Hz}$ or $2.5 \mathrm{rad} / \mathrm{sec}$. This is much higher than the vertical-rate commandsystem bandwidth of the vehicle, which is $0.3 \mathrm{rad} / \mathrm{sec}$. According to Table 2, the pilot's primary function would therefore be to provide rate. According to Table 3, the principal simulation cue for the task would then be vertical velocity. The OTW would have provided the vertical-velocity cues, and the motion system would have provided the acceleration cues. When motion was absent in the study, the altitude response exhibited an under-damped characteristic. As motion cueing fidelity increased, an improved altitude-damping response was observed, although the motion platform's equivalent time delay lagged the visual transport delay by 80 msec (60 msec vs. $140 \mathrm{msec}$ ). This indicates that pilots were obtaining the vertical-velocity feedback by integrating cues perceived via vestibular or proprioceptive mechanisms to improve damping for the attitude stabilization. ${ }^{13}$

\section{Review Study \#3: Schroeder, Chung and Laforce's sidestep experiment ${ }^{7}$}

1. Validity and Reliability

The study provides valid data on the effects of false coordinated roll-lateral motion cues on pilot-helicopter performance and pilot control inputs (workload). Subjective motion-fidelity ratings and handling-quality ratings 
were also collected. Each of the three pilots experienced all configurations in random order, which reduced within-group variability and adaptation effects. No statistics or power analyses are provided.

2. Effect of Motion Cues

1) Task: A 20-ft lateral offset maneuver of a rotorcraft. The stabilization at the stationkeeping point is a compensatory task.

2) Vehicle dynamics: Roll and lateral vehicle dynamics were a combined fourth-order singleloop multi-DOF system as shown in Fig. 6 and described by Eq. (8), where $L_{p}=-4.5 \mathrm{rad} / \mathrm{sec}$.

$$
\frac{y}{\delta_{\text {Lat }}}=\frac{K_{P V}}{s^{3}\left(s+L_{P}\right)}
$$

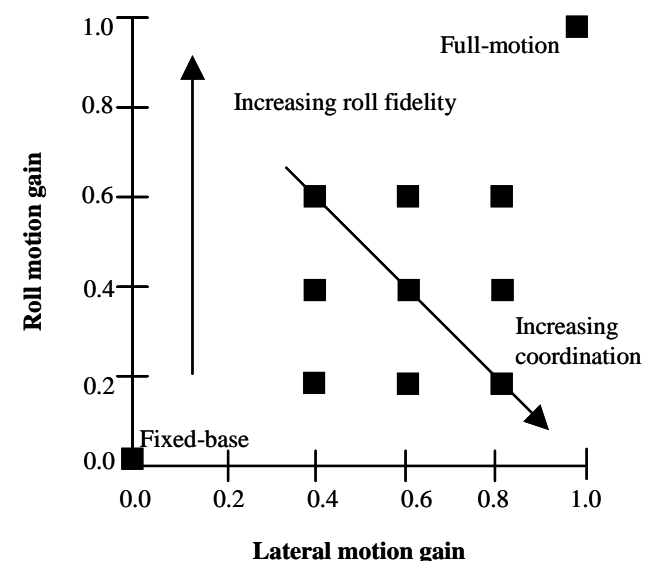

Figure 7. Motion gain configuration investigated in Review Study \#3.

3) Visual cues: The simulator cockpit had a

horizontal FOV of $\pm 78^{\circ}$ and vertical FOV of $10^{\circ}$ up and $15^{\circ}$ down, with clearly marked ground reference (black and white stripes on the ground) during translation. Visual-cue delay was $60 \mathrm{msec}$.

4) Motion cues: Motion commands were scaled from 0 (fixed-base, no motion) to 1.0 (full motion, one-to-one scale) for both roll and lateral motion axes to test roll-motion fidelity and lateral-coordination requirements as shown in Fig. 7. No washout filter was used.

5) Conclusions from the study: This study found roll and lateral motion-gain variation to be important for pilots' subjective perception of handling qualities and simulation fidelity, but not for their positioning performance. Lateral cues appeared important for this latter task.

6) Lessons learned: Following the crossover model, the pilot transfer function for the given task is of the type $\mathrm{Y}_{\mathrm{Pe}}=\mathrm{K}_{\mathrm{PS}}{ }^{2}(\mathrm{~s}+\mathrm{a}) \mathrm{e}^{-\tau \mathrm{s}}$. The pilot's primary function is acceleration with a lead. From Table 3, the information from visual cues would be limited and the principal motion cues would be accelerations. Indeed, the time history data suggest that pilots used the motion cues to generate lead or to integrate them to obtain lateral velocity information for improved lateral hover position control.

\section{Review \#4: V1 cut takeoff from Go et al. ${ }^{10}$}

\section{Validity and Reliability}

The data presented are part of a study examining the effect of hexapod motion on recurrent airline-pilot evaluation and training, using a quasi-transfer paradigm. The training phase of the study (where the pilots were told which maneuver they would experience and were given the chance to repeat it three times) is singled out to demonstrate the application of the proposed approach. The data provide a valid answer to the question of whether motion affects pilot-vehicle performance and pilot behavior in the simulator. Both objective and subjective data were collected on these dependent variables. For the no-motion configuration, the simulator was initialized as for motion and then the motion washed out without knowledge of the pilots to prevent pilot bias. The equipment was carefully calibrated. Pilots experienced only one of the two motion conditions to prevent order and learning effects. They were counterbalanced across groups based on their experience. Power analyses showed that even in the cases where no effect of motion was found, the resolution of the experiment was such that any operationally relevant effect could have been found. ${ }^{10}$ This required that 40 airline captains and first officers qualified for the simulated airplane participated in the experiment.

\section{Effect of Motion Cues}

1) Task: Stabilize airplane (B747-400) heading after engine failure at $V_{1}$. This is a compensatory task.

2) Vehicle dynamics: Directional motion was dominant for a few seconds after the engine failure. The yaw dynamics during this time frame can be approximated by a first-order rate-command system.

3) Visual cues: The visual system of the simulator had $180^{\circ}$ horizontal and $40^{\circ}$ vertical FOV with high brightness and high resolution. Visual cueing transport delay of the simulator was about $130 \mathrm{msec}$.

4) Motion cues: The motion system consisted of a 6-DOF synergistic hexapod platform with a 48 inch stroke and a $9 \mathrm{~Hz}$ bandwidth. Yaw motion was traded off for improved lateral acceleration cues based on Sinacori-type 
criteria. ${ }^{12,14}$ Cockpit side force was simulated by combining tilt and a high-pass washout filter of medium fidelity. Transport delay of the motion cues was about 90 msec.

5) Conclusions from the study: The results showed that motion cues affect pedal-reaction time. No effect on performance due to this reaction-time difference was found, however, probably due to the relatively sluggish dynamics of the airplane.

6) Lessons learned: Because the airplane's dynamic-bandwidth was relatively low, the heading control system can be considered an acceleration system. Therefore, according to Table 2, the pilot's primary function is to provide rate. According to Table 3, the motion cues would be important to provide the principal cue for the task, i.e., yaw rate, especially with minimal runway visual range. This principal cue, however, was not available due to the motion-system adjustment tradeoff mentioned above. Because the pilot position in the airplane is far in front of the c.g., the yaw motion induced lateral-acceleration at the pilot station. Pilots apparently used these lateral acceleration cues to reduce their reaction time to the engine failure.

\section{Discussion of Approach}

The approach uses the open-loop pilot-vehicle characteristics to clarify complex interactions between pilots' control function and simulation cues based on type of task. Based on this approach, the concept of principal cues is constructed as a starting point to determine the cues pilots are using for a given task. In the limited number of reviews conducted, this approach provides physics-based insights into the relationship between the results of the study and how pilots use visual and motion cues. Contrary to expectation, the approach reveals that there is no linear relationship between principal cues and pilot-vehicle behavior. This appears to result from the fact that pilots use not only principal cues, which are defined as direct cues that do not require extensive processing, but also combine and process (e.g., integrate or differentiate) supplemental cues to extract the information necessary to successfully complete their tasks. This finding will be used to refine the procedure further.

It should be noted that this approach is not an attempt to solve how motion cues affect pilot-vehicle behavior and performance issues that past studies tried to address. Rather, it offers a systematic process to review past studies to extract additional lessons and guidance for future experiments. No attempt was made to address aural and controlinceptor cues, which may also affect pilot-vehicle behavior. This will be left to future elaborations of the approach.

The approach requires that a study documents experiment design, vehicle dynamics and visual and motion cueing characteristics sufficiently to allow this kind of in-depth review. Even in the absence of this documentation, however, the approach may help develop a better understanding of the interaction between pilot-vehicle performance and behavior and simulation cues.

\section{Summary of Lessons Learned}

The lessons learned from the four studies reviewed are summarized in Table 4.

Table 4. Summary of lessons learned from four studies reviewed by the approach

\begin{tabular}{|c|c|c|c|c|c|c|c|c|c|}
\hline Author & Task & $\begin{array}{c}\text { Simulate } \\
\text { d vehicle } \\
\text { type }\end{array}$ & $\begin{array}{c}\text { Vehicle } \\
\text { dynamics }\end{array}$ & DOF & $\begin{array}{l}\text { Estimated } \\
\text { pilot } \\
\text { function }\end{array}$ & Visual cues & $\begin{array}{l}\text { Motion } \\
\text { cues }\end{array}$ & Results & Remarks \\
\hline Schroeder $^{12}$ & $\begin{array}{c}\text { Heading } \\
\text { stabilization }\end{array}$ & Rotorcraft & $\begin{array}{c}\text { Yaw rate, } \\
\omega_{\mathrm{BW}}=0.27 \\
\mathrm{rad} / \mathrm{sec}\end{array}$ & $\begin{array}{l}\text { Yaw } \\
\text { and } \\
\text { lateral }\end{array}$ & $\mathrm{K}_{\mathrm{P}} \mathrm{se}^{-\tau \mathrm{s}}$ & $\begin{array}{l}\text { FOV: } \pm 40^{\circ} \\
\text { horizontal, } \\
+10^{\circ} /-15^{\circ} \\
\text { vertical } \\
\text { (front } \\
\text { window); } \\
60 \text { msec } \\
\text { transport } \\
\text { delay }\end{array}$ & $\begin{array}{l}\text { Full- } \\
\text { motion, no } \\
\text { washout } \\
\text { filter; } \\
130 \text { msec } \\
\text { delay for } \\
\text { yaw and } \\
\text { sway }\end{array}$ & $\begin{array}{l}\text { Yaw motion } \\
\text { has no } \\
\text { effect. } \\
\text { Lateral } \\
\text { motion } \\
\text { effect is } \\
\text { significant. }\end{array}$ & $\begin{array}{l}\text { Yaw motion } \\
\text { has no effect. } \\
\text { Pilots } \\
\text { integrate } \\
\text { lateral motion } \\
\text { cues to } \\
\text { improve yaw } \\
\text { rate feedback }\end{array}$ \\
\hline Schroeder $^{12}$ & $\begin{array}{c}\text { Vertical } \\
\text { stabilization }\end{array}$ & Rotorcraft & $\begin{array}{c}\text { Vertical } \\
\text { speed, } \\
\omega_{\mathrm{BW}}=0.3 \\
\mathrm{rad} / \mathrm{sec}\end{array}$ & Vertical & $\mathrm{K}_{\mathrm{P}} \mathrm{se}^{-\tau \mathrm{s}}$ & $\begin{array}{l}\text { FOV: } \pm 78^{\circ} \\
\text { horizontal, } \\
+10^{\circ} /-15^{\circ} \\
\text { vertical } \\
\text { (front } \\
\text { window); } \\
60 \text { msec } \\
\text { transport } \\
\text { delay }\end{array}$ & $\begin{array}{l}\text { Varied } \\
\text { washout } \\
\text { filter gain } \\
\text { and } \\
\text { frequency; } \\
140 \text { msec } \\
\text { delay for } \\
\text { vertical }\end{array}$ & $\begin{array}{l}\text { Vertical } \\
\text { motion has } \\
\text { effects on } \\
\text { pilot } \\
\text { performance } \\
\text { and } \\
\text { subjective } \\
\text { motion } \\
\text { fidelity }\end{array}$ & $\begin{array}{l}\text { Pilots } \\
\text { integrate } \\
\text { vertical } \\
\text { acceleration } \\
\text { to improve } \\
\text { vertical } \\
\text { velocity } \\
\text { feedback }\end{array}$ \\
\hline $\begin{array}{c}\text { Schroeder } \\
\text { and Chung }\end{array}$ & Sidestep & Rotorcraft & $\begin{array}{l}\text { Roll rate, } \\
\omega_{\mathrm{BW}}=4.5\end{array}$ & $\begin{array}{l}\text { Roll } \\
\text { and }\end{array}$ & $\begin{array}{c}\mathrm{K}_{\mathrm{P}} \mathrm{s}^{2}(\mathrm{~s}+\mathrm{a}) \\
\mathrm{e}^{-\tau \mathrm{s}} \\
\end{array}$ & $\begin{array}{l}\text { FOV: } \pm 78^{\circ} \\
\text { horizontal, }\end{array}$ & $\begin{array}{l}\text { Varied roll } \\
\text { and lateral }\end{array}$ & $\begin{array}{l}\text { Both roll } \\
\text { and lateral }\end{array}$ & $\begin{array}{l}\text { Better } \\
\text { understanding }\end{array}$ \\
\hline
\end{tabular}




\begin{tabular}{|c|c|c|c|c|c|c|c|c|c|}
\hline Author & Task & $\begin{array}{c}\text { Simulate } \\
\text { d vehicle } \\
\text { type } \\
\end{array}$ & $\begin{array}{c}\text { Vehicle } \\
\text { dynamics }\end{array}$ & DOF & $\begin{array}{c}\text { Estimated } \\
\text { pilot } \\
\text { function }\end{array}$ & Visual cues & $\begin{array}{l}\text { Motion } \\
\text { cues }\end{array}$ & Results & Remarks \\
\hline & & & $\mathrm{rad} / \mathrm{sec}$ & lateral & & $\begin{array}{l}+10^{\circ} /-15^{\circ} \\
\text { vertical } \\
\text { (front } \\
\text { window); } \\
60 \text { msec } \\
\text { transport } \\
\text { delay }\end{array}$ & $\begin{array}{l}\text { gains, no } \\
\text { washout } \\
\text { filter; } \\
60 \text { msec } \\
\text { delay for } \\
\text { roll and } \\
\text { lateral }\end{array}$ & $\begin{array}{l}\text { motion } \\
\text { affect } \\
\text { pilots' } \\
\text { perception } \\
\text { and control } \\
\text { activities, } \\
\text { but not } \\
\text { performance }\end{array}$ & $\begin{array}{l}\text { for multi-axis } \\
\text { maneuver } \\
\text { needs to be } \\
\text { developed }\end{array}$ \\
\hline Go et al. ${ }^{10}$ & V1 cut & Transport & Yaw rate & $\begin{array}{l}\text { Yaw } \\
\text { and } \\
\text { lateral }\end{array}$ & $\mathrm{K}_{\mathrm{P}} \mathrm{se}^{-\tau \mathrm{s}}$ & $\begin{array}{l}\text { FOV: } 180^{\circ} \\
\text { horizontal, } \\
40^{\circ} \\
\text { vertical; } \\
130 \text { msec } \\
\text { transport } \\
\text { delay }\end{array}$ & $\begin{array}{l}\text { Medium } \\
\text { fidelity for } \\
\text { lateral, no } \\
\text { yaw } \\
\text { motion; } \\
90 \text { msec } \\
\text { delay }\end{array}$ & $\begin{array}{l}\text { Motion cues } \\
\text { had an } \\
\text { effect on } \\
\text { pedal } \\
\text { reaction } \\
\text { time }\end{array}$ & $\begin{array}{l}\text { Pilots use } \\
\text { lateral } \\
\text { acceleration } \\
\text { cue for faster } \\
\text { pedal } \\
\text { response to } \\
\text { engine failure }\end{array}$ \\
\hline
\end{tabular}

\section{Concluding Remarks}

1) An approach based on pilot-vehicle closed-loop control theory is developed to aid the interpretation of past studies investigating motion cueing effects.

2) The review process helps to develop a systematic understanding of factors that may determine the effectiveness of motion cues in a ground-based flight simulation, but needs further adjustment to include consideration of other simulation cues such as control inceptor cues and aural cues.

3) The process helps to define the relationship between pilot-vehicle behavior and simulation cues.

4) Detailed documentation of vehicle dynamics and visual and motion cueing characteristics are recommended for future studies investigating the effect of simulation cues.

\section{Acknowledgments}

The authors thank Dr. Eleana Edens from the FAA Human Factors Division, AAR-100, and Dr. Thomas Longridge from the FAA Flight Standards Service, AFS-230, for helpful comments and supports of this work. We also thank Dr. Jeffery Schroeder who has volunteered his time to review the paper and provided valuable suggestions.

\section{References}

${ }^{1}$ McRuer, D.T., and Krendel, E.S., “Mathematical Models of Human Pilot Behavior,” AGARD-AG-188, 1974.

${ }^{2}$ Parrish, R.V., Dieudonne, J.E., Bowles, R.L., and Martin, Jr., D.J., “Coordinated Adaptive Washout for Motion Simulators,” Journal of Aircraft, Vol. 12, No. 1, Jan., 1975, pp. 44-50.

${ }^{3}$ Grant, P.R., and Reid, L.D., “Motion Washout Filter Tuning: Rules and Requirements,” AIAA-95-3408, August 1995.

${ }^{4}$ McRuer, D.T. , "Pilot Modeling," AGARD-LS-157, 1988.

${ }^{5}$ Stapleford R. L., Peters, R. A., and Alex, F. R., "Experiments and a Model for Pilot Dynamics with Visual and Motion Inputs,” NASA CR-1325, May 1969.

${ }^{6}$ Young, LR., ”Visually Induced Motion In Flight Simulation,” AGARD-CP-249, Piloted Aircraft Environment Simulation Techniques, Brussels, Belgium, April 1978.

${ }^{7}$ Schroeder, J. A., Chung, W. W., and LaForce, S., "Effects of Roll and Lateral Flight Simulation Motion Gains on a Sidestep Task,” American Helicopter Society 53rd Annual Forum, Virginia Beach, Virginia, May 1997.

${ }^{8}$ Mikula, J., Chung, W. W., and Tran, D., “Motion Fidelity Criteria for Roll-Lateral Translational Tasks,” AIAA 99-4329, 1999.

${ }^{9}$ Taylor, H. L., Lintern, G., and Koonce, J. M., “Quasi-Transfer as a Predictor of Transfer from Simulator to Airplane,” The Journal of General Psychology, 120(3), 1993, pp. 257-276.

${ }^{10}$ Go, T. H., Bürki-Cohen, J., Chung, W. W., Schroeder, J. A., Saillant, G., Jacobs, S., and Longridge, T., "The Effects of Enhanced Hexapod Motion on Airline Pilot Recurrent Training and Evaluation,” AIAA-2003-5678, 2003.

${ }^{11}$ Cohen, J., Statistical Power Analysis for the Behavioral Sciences, $2^{\text {nd }}$ ed., Lawrence Erlbaum Associates, Hillsdale, New Jersey, 1988.

${ }^{12}$ Schroeder, J. A.: "Helicopter Flight Simulation Motion Platform Requirements, " NASA TP-1999-208766, July 1999.

${ }^{13}$ Hess, R. A., and Siwakosit, W., “Assessment of Flight Simulator Fidelity Including Visual Cue Quality,” Journal of Aircraft, Vol. 38, No. 4, 2000, pp. 607-614.

${ }^{14}$ Sinacori, J. B., “The Determination of Some Requirements for a Helicopter Flight Research Simulation Facility,” NASA CR-152066, 1977. 